\title{
Co-management Economic Solutions for Marine Protected Area in Punta Cana: a Study of Key Players and Potential Partnerships in Conserving the Coastal Marine Ecosystem
}

\author{
Jahza Klochko and Brendan Francis \\ University of Florida
}

Faculty mentor: Jocelyn Widmer, TAMU

\begin{abstract}
A comprehensive research study of Cabeza de Toro and Punta Cana's fishing and tourism industries reveal viability of economic solutions between the hospitality industry, fishermen, and the government to reduce practices harmful to the coastal marine ecosystem. Recent research studies of Punta Cana and Cabeza de Toro's coastal marine ecosystem demonstrate diminishing coral coverage and reduced fish populations. Causes for the decline of the coastal marine ecosystem include overfishing, illegal fishing of species conducive to coral health, and the destruction of mangrove sanctuaries. By methods of survey and in-person interview, researchers gathered data on over $20 \%$ of Cabeza de Toro's fisherman population with the intent of further developing a co-management plan for the recently established marine protected area. Data collection included qualitative and quantitative research into income and livelihoods of Cabeza de Toro fishermen, fishing practices, interest in alternative work opportunities, and strength of social responsibility and environmental beliefs. Findings demonstrate that viable economic applications exist in forging partnerships between fishermen, the tourism and hospitality industries, and the local government.
\end{abstract}

Keywords: marine protected area, co-management plan, coastal marine ecosystem

\section{Introduction}

In 2018, five undergraduate students from the University of Florida travelled to the Dominican Republic with the express purpose of researching solutions for a diminishing marine ecosystem in Cabeza de Toro and Punta Cana. A 2001 study of stony corals in Punta Cana showed that the coverage of coral was below average (Burr, 2001), and a 2015 study that compared nine coral reef systems in the Dominican Republic found that Punta Cana's coral reef coverage was the lowest in the sample (Steneck and Torres 2015). Present research suggests that this may be due to overfishing (Brandt, Cooper, Polsenberg, 2003), and while causation has not been completely established, it is likely that the reduction of the parrotfish population is also an influencing factor (Steneck and Torres, 2015). Another cause of the diminishing coastal marine ecosystem is the destruction of mangrove sanctuaries. Beachfront property provides businesses in the hospitality 
industry a lucrative location for resorts, which are aiming to serve tourists who are attracted to the beach. This has caused many Punta Cana hotels to build their resorts directly atop crucial mangrove sanctuaries. Mangrove sanctuaries are crucial habitats for fish to lay eggs, so their destruction has been a contributing factor to the decimation of the fish population.

To address these issues, a marine protected area (MPA) is to be established in the area around 2020. The Dominican Republic's Ministry of Environment and Natural Resources announced in February 2018 that a partnership with Blue Finance, an NGO organized through the United Nations, would be the means by which nearly 5,000 square miles of MPA will be managed. The purpose of this co-management agreement is to introduce financially sustainable solutions to marine conservation in securing private investors, thus reducing complete dependence upon government financing (Avery, 2018). Tasked with furthering the development of this comanagement plan for the recently established MPA, this research team conducted research alongside the Fundacion Grupo Puntacana to better understand the local economic environment, with the intention of recommending alternative revenue streams for those fishermen who could potentially be displaced by conservation efforts, as well as offering solutions to reduce practices destructive to the coastal marine ecosystem.

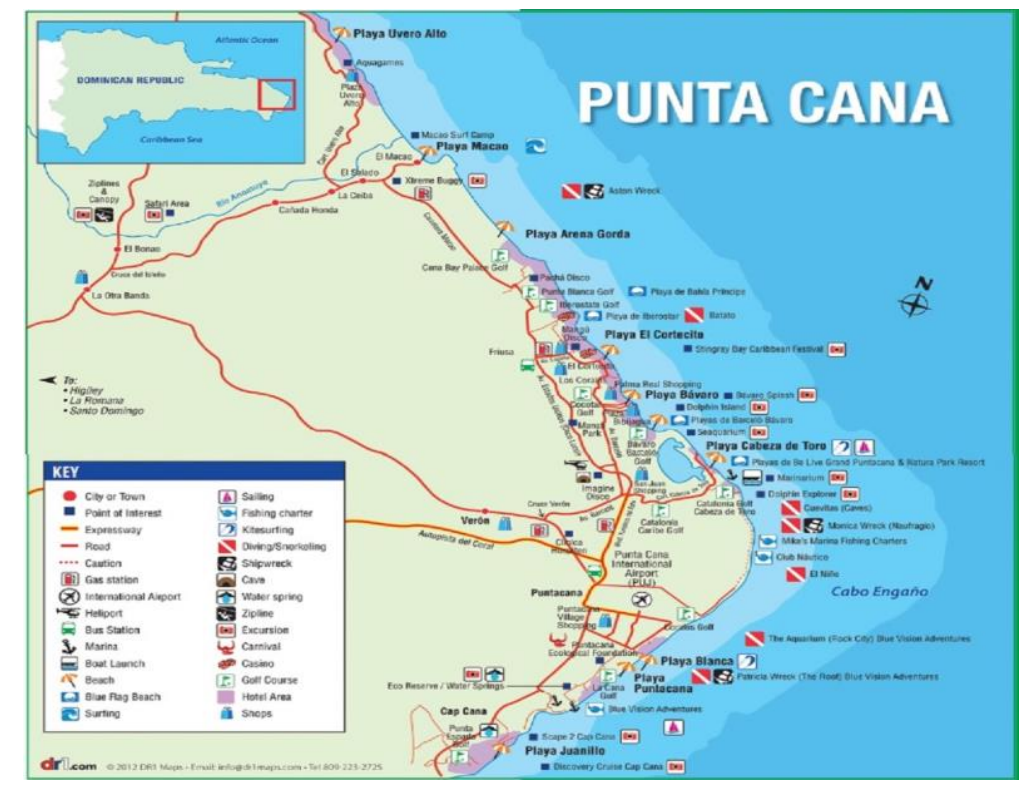

Figure 1: Map depicting the location of Cabeza de Toro, Punta Cana, and other geographic landmarks. Credits to: punta-cana.info 
This research studies the economic underpinnings of Punta Cana and Cabeza de Toro, two separate communities that are close in proximity. Punta Cana draws a great deal of wealth due to the tourism and hospitality industry, whereas Cabeza de Toro is less wealthy but popular for its fishing. Presently, there is minimal economic partnership between the hospitality industry of Punta Cana and the fishing industry of Cabeza de Toro. Rather, the hospitality industry in Punta Cana outsources much of their seafood purchases, a decision based upon the capability of outside markets to provide consistent, inexpensive seafood in mass quantities. Local Cabeza de Toro fishermen oftentimes do not have the economic means to pay to deep freeze their fish or ship their fish elsewhere for deep freeze storage, which are two barriers to their execution of large quantity sales. Additionally, the hospitality industry of Punta Cana outsources employment, as local Cabeza de Toro residents do not have the necessary qualifications to be hired. This research culminates in a proposal developing economic solutions for reducing illegal fishing, promoting the Cabeza de Toro fishing industry, providing alternative work opportunities for displaced fishermen, protecting mangrove sanctuaries, and increasing agency of a third party regulatory entity in Asociación de Pescadores Cabeza de Toro.

\section{Methodology}

The methodology for this research design study employed a hybrid of interviews and surveys, entailing both qualitative and quantitative methods for data collection. Surveys were designed for Cabeza de Toro fishermen to better understand demographics, motivations personal and economic, fishing practices, interest in alternative work opportunities, and responsibility to the environment. The means of conducting and recording these surveys was the mobile application Fulcrum. During a 2 week period, researchers administered surveys in Spanish and recorded responses in the application. This method of data collection also permitted for extensive interviews, each of which ranged from 30 to 40 minutes per participant. Outside of fisherman who participated in surveys, data was collected via qualitative interview with other related parties - such as businessmen in the fishing industry, managers in industries of hospitality and tourism, as well as local vendors. 


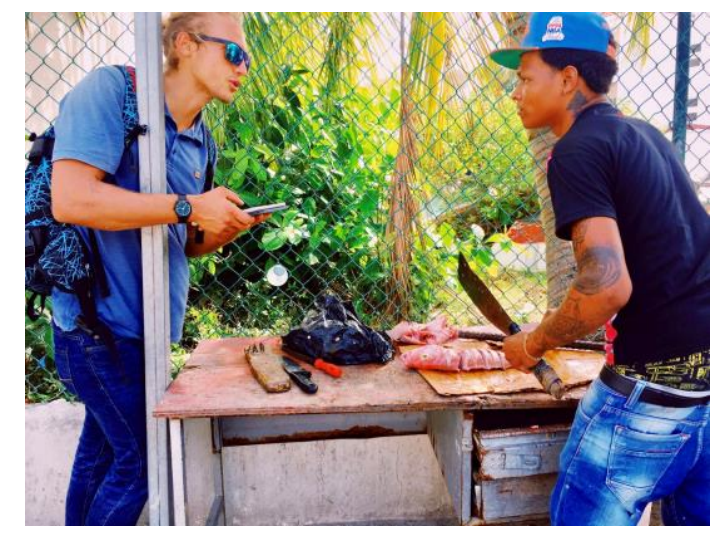

Figure 2: Researcher Jahza Klochko conducting interview with Cabeza de Toro fisherman.

This study collected data from 23 participants that presents an adequately representative and diverse range of characteristics among Cabeza de Toro fishermen, while still maintaining a proportionally representative expression to the overall fishing community of Cabeza de Toro. Participants were selected randomly with the help of the local community leaders, who helped identifty the areas in which the fisherman would congregate, where their businesses were located, and where to find them as they left and returned on fishing trips. Participants were selected from different locations, at different times and with different interests/fishing practices. There are approximately 100 fishermen in the Cabeza de Toro Fisherman Association (Asociación de Pescadores Cabeza de Toro), thus the interviews conducted comprise a fairly large percentage of public opinion within the fishing community.

\section{Results}

\section{Demographics}

Of the 23 participants in this study, all were male, which is typical considering cultural attitudes towards the occupation. The participants' levels of highest educational attainment were varied, with 10 having completed primary education, 11 having completed high school, and 2 having earned college degrees. 22 of the participants were Dominican, and 1 identified as Haitian. 15 of the participants were locals to Cabeza de Toro, and 8 came from neighboring towns of Higuey, Verón, and Ningún. 21 of the 23 participants resided in Cabeza de Toro or the surrounding communities throughout the entire year. 13 were married, and 10 were still single. 19 of the participants stated that fishing was their main source of income, with 3 receiving their 
main source of income from tourism and 1 from agriculture. A number of the fisherman also worked in other industries, such as tourism, construction, community business, taxi driving, and boat making. All things considered, the participant pool presents a sample that composed a substantial percentage of the fisherman population (over 20\%), provides for a representative expression of Cabeza de Toro fishermen, and strikes a balance between diversity and proportionality to the larger fishing population.

\section{Economic and Personal Motivations}

First, with regards to the fishermen's economic livelihoods, surveys and interviews indicated valuable results regarding income incentives and personal motivations. The main reason that the participants had decided to live in Cabeza de Toro was due to the work opportunities (65.3\%) other reasons including proximity to family (17.4\%), native to the community $(8.7 \%)$, security (4.3\%), and one answer indicating all of the above (4.3\%). When the participants were asked why they fish, they were permitted to respond with more than one reason, eliciting the following results: $52.2 \%$ fished for enjoyment, $47.8 \%$ for the high economic value, $17.4 \%$ because it is their best ability, and $17.4 \%$ because there are no alternative jobs available.

\section{Fishing practices}

Second, important trends were discovered concerning economic capabilities and existing capital of local fisherman that assist in explaining the harmful fishing practices undertaken. 18 of the 23 fishermen surveyed had never taken out a loan, nor did they own their own boat. In fact, 10 of the 23 fishermen said they had to rent a boat when they wished to fish farther out from the coast. These economic limitations are important in assessing the economic motivations that influence $30 \%$ of fisherman to fish on the reefs. Approximately half of all the fishermen fish for Red Snapper farther off the coast away from the reefs, a practice that is of little known harm to the reefs. However, $47 \%$ spearfish and dive using compressors, many of them diving directly from the coast, and of the fishermen who spearfish, $63 \%$ admit to fishing on the reef. Interviews indicate that the majority of spearfishermen are younger and without the necessary economic means to rent boats or buy equipment essential to fishing farther out at sea. These practices of fishing on the reefs are contributing factors to the diminishing and endangered coral reefs and marine ecosystem of Cabeza de Toro. 


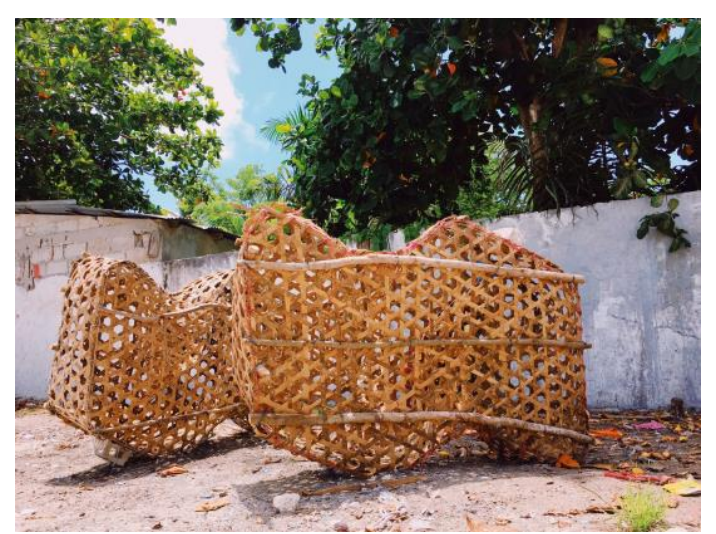

Figure 3: Fish traps: Alternative method of fishing to spearfishing, especially conducive to selective fishing, a method of fishing less harmful to the environment.

\section{Interest in Alternative Work Opportunities}

Third, surveys and interviews show that the participants were highly open to work opportunities other than fishing. Since the grand majority of the fishermen do not have boats, their level of investment in their present career is considerably lower than those who would. Additionally, the amount of educational investment that the participants had put into fishing was negligible: only $13 \%$ had received any formal education in the occupation. Presented with the opportunity of educational courses, $82 \%$ would develop skills in another marine based occupation, $52 \%$ as a tour guide or chauffeur, $43 \%$ in the food service industry, $26 \%$ in agriculture in construction, and $13 \%$ as an artisan.

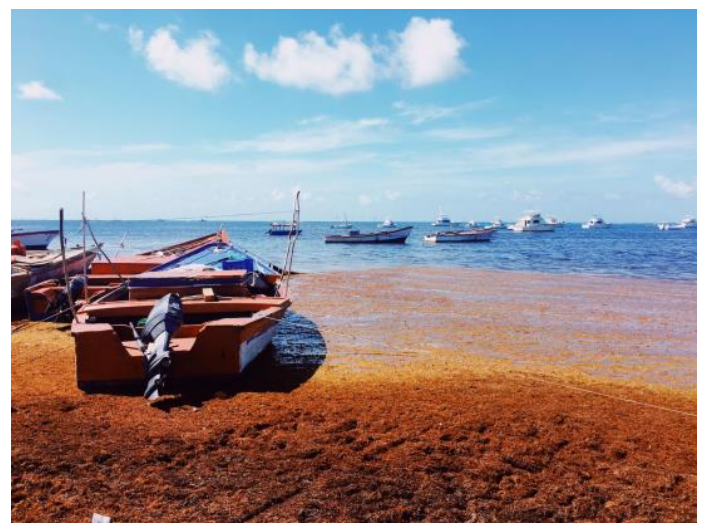

Figure 4: While excessive algae has threatened the balance of the marine ecosystem, the need for its reduction can provide marine-based jobs for fishermen seeking alternative work opportunities. 


\section{Social Responsibility and Environmentalism}

Fourth, Cabeza de Toro fishermen already possess an innately strong level of social responsibility and value for the marine ecosystem. When asked to assign responsibility for the solving of marine natural resource problems in the area, $78 \%$ responded that they believed the local fishermen held responsibility in this area. Additionally, when asked for the reason for the reduced fish population in the Cabeza de Toro's marine ecosystem, $48 \%$ of participants indicated that overfishing was a cause. Cabeza de Toro fishermen also possess a high value for the marine ecosystem. $83 \%$ responded that it was "very important" to preserve, while the other $17 \%$ viewed the issue as "important."

\section{Discussion}

\section{Viability}

As a prerequisite to ascertaining whether or not solutions are worthwhile to propose, the viability and potential of adoption of solutions should be determined. The first strong indicator of the viability of proposed solutions is the high degree of social responsibility held by Cabeza de Toro fisherman towards their marine ecosystem, as well as the relatively large population who admits that overfishing is a contributing factor. The second indicator that economic solutions are feasible is the degree of openness that Cabeza de Toro fishermen hold with regards to the possibility of alternative work opportunities. Furthermore, the results indicate that reasons for illegal and harmful fishing practices are economically motivated, since many fishermen do not have the economic means to fish in waters farther away from the coast. This is to say that while the desire for responsible fishing is strong, many fishermen lack the economic means to do so, which pushes many to spearfish on the reefs or to overfish species that are crucial for the preservation of the coral reefs, such as parrotfish. The solutions proposed are to provide Cabeza de Toro fishermen the economic investment through partnership to allow them to fish farther away from the coast, as well as facilitating the transition of some fishermen to alternative work opportunities. Additional solutions address the destruction of mangrove sanctuaries and the need for a strong third party regulatory entity in Cabeza de Toro's fishing community. 


\section{Solutions in the Hospitality Industry}

The first area of recommendation comes at the intent to provide Cabeza de Toro fishermen the economic means to fish farther out from the coast, through partnership from the hospitality industry. Presently, the hospitality industry in Punta Cana does not invest heavily in the local fishing economy. Instead, hotels elect to purchase their seafood from markets in Rio San Juan and Puerto Plato, a decision based upon the ability of outside markets to provide consistent, inexpensive seafood in mass quantities. Local Cabeza de Toro fishermen oftentimes do not have the economic means to pay to deep freeze their fish or ship their fish elsewhere for deep freeze storage, which are two barriers to their execution of consistent large quantity sales. With an investment to provide inexpensive, centralized deep freezer access to local fishermen, economic partnerships between Punta Cana hotels and Asociación de Pescadores Cabeza de Toro would be made possible. With fishermen able to make a better wage from fishing legally, this provides less of an incentive for fishermen continue fishing practices harmful to coral reefs, whether it be spearfishing on the reefs or hunting parrotfish. Additionally, this relationship would provide for third party regulation from Asociación de Pescadores Cabeza de Toro, who would regulate these sales. The implementation of a third party entity holds potential to reduce illegal lobster and conch fishing, as well as other overfishing. The source of this initial investment will likely come from either the local or national government, or the hotels themselves, as the local fishermen will likely not have the equity or credit to apply for and receive such a loan. The sustainability of this solution is possible through continued economic partnership between the hospitality industry of Punta Cana and the fishermen and fishing association of Cabeza de Toro.

This burgeoning economic partnership would result in a stronger relationship between hotels and fishermen, which has the potential to spill over into other facets of business beneficial to both parties. Survey research showed that $68 \%$ of fishermen surveyed claim they do not have a good relationship with local Hotel or Resorts, and the local attitude towards the hospitality industry is overwhelmingly negative, considering that the hotels are not investing in the local economy by buying seafood locally or employing locals. The present attitude of locals in Punta Cana and Cabeza de Toro is overwhelmingly negative towards tourism, as it is not seen as a help to the economy. This public sentiment has lead to issues of vendors harassing tourists on beaches. However, this economic partnership has the ability to foster positive public sentiment towards hotels and tourism, as well cultivate a wide range of alternative employment 
opportunities for locals. Currently, hotels outsource to Santo Domingo, Higuey, and San Juan for their employees. The main barriers to the hospitality industry's hiring of locals include a lack of training that locals hold in careers in hospitality and a lack of ability to speak English. Surveys indicate that $43 \%$ of fishermen would be interested in alternative careers in the food service industry, and 52\% would be open to an alternative income stream from tourism. Hotels have numerous opportunities for tourism that go relatively untapped by locals, including scuba diving trips, parasailing expeditions, and catamaran ships that take 5 to 7 trips daily. The hiring of local fishermen would reduce the incentive for fishermen to undertake illegal and environmentally harmful fishing practices in order to earn an income. So while an economic partnership with regards to employment would surely benefit fishermen, it would also greatly aid the tourism and hospitality industry. Additionally, with regards to the hospitality industry in Punta Cana, there must be an increased investment in preserving the local marine ecosystem, for it is a main attraction for tourists. If the coral reefs are preserved, then the hospitality industry will also be preserved, as this facet of Punta Cana is a substantial reason for tourism.

\section{Solutions for Government}

Currently, numerous beachfront hotels have been built upon the land that was once home to mangroves, which are a variety of species of trees and bushes that grow on beaches. These mangroves are of crucial importance to the preservation of the coral reefs and marine ecosystem because they are the habitat where fish lay their eggs. However, with these habitats destroyed, many fish no longer have a home to reproduce, thus decreasing the fish population. While constructing hotels on beachfront property may seem economically desirable in the short-term from a location perspective, this placement of hospitality resorts actually works counterproductive to their overall long-term goals of preserving tourism, as they are destroying the marine ecosystem that attracts tourists to Punta Cana. Education and activism are methods for ceasing this habitat destruction, and it is possible that the hospitality industry may realize their dependence on the marine ecosystem to sustain tourism. However, the ultimate responsibility rests upon respective government entities to prevent further destruction of mangrove sanctuaries due to economically lucrative incentives.

One other important role that the government can play is in facilitating the transition of fishermen from their present work of fishing to alternative work opportunities. While data 
shows that the majority of fishermen are interested in alternative careers, many lack the necessary education and training to successfully integrate into new employment openings. This assistance could take the form of government sponsored educational courses to provide fishermen the language capabilities or occupational skills to work in the tourism or hospitality industries in the area. Furthermore, the government could provide fishermen alternative work opportunities in the form of marine based jobs. Microfragmenting coral is a new technique that has been shown to boost growth of diminishing coral reefs, and mangrove restoration will be an important facet of rebuilding the habitat for fish to reproduce. Additionally, algae blooms have been a growing issue in Punta Cana, as the massive quantity of algae disrupts the marine ecosystem and also damages the experiences of tourists. These three environmental solutions microfragmentation, mangrove restoration, and algae reduction - can provide alternative occupations for fishermen, a solution that can assist the transition of fishermen to alternative work opportunities, improve the marine ecosystem, and generate growth within the tourism industry.

\section{Asociación de Pescadores Cabeza de Toro}

The local fishing community is organized around the Cabeza de Toro fishing association Asociación de Pescadores Cabeza de Toro - but there exists issues with compliance and participation from outsider fishermen. Our research indicated that there exists a sizable portion of the fisherman population that has yet to become associated with the Cabeza de Toro fishing association: roughly one in every five fishermen is not associated. While those who are associated are social responsible to the Cabeza de Toro community, their land, and their ocean, those who are not associated often come from neighboring towns like Veron and Higuey to spearfish on the reefs. This practice of spearfishing on local reefs is believed to be a contributing factor to the diminishing coral reef system, and is illegal under local law. Especially considering the viability of Asociación de Pescadores Cabeza de Toro becoming a third party regulatory entity, the incorporation of fishermen who reside outside of Cabeza de Toro into Asociación de Pescadores Cabeza de Toro would improve adherence to regulations, thus improving the state of the coastal marine ecosystem. 


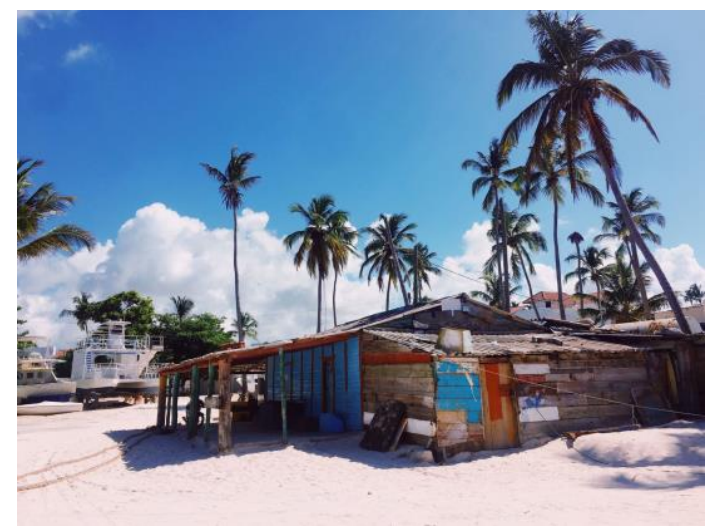

Figure 5: Local fishing huts are not yet suited to provide for the demands of a booming Punta Cana hospitality industry.

\section{Conclusion}

The proposed solutions come from a multidimensional feasibility study that indicates a promising future for the possibility to a mutually beneficial partnership between Cabeza de Toro fishermen, the hospitality industry of Punta Cana, and the government - a viability demonstrated through research in environmental responsibility, openness to alternative careers, and economic motivations for harmful fishing practices. With the understanding that the coastal marine ecosystem has an impact upon the tourism industry, the hospitality industry of Punta Cana has a vested interest in offering financial partnership to Cabeza de Toro fishermen so as to reduce illegal spearfishing within reef areas. This financial partnership also has the potential to strengthen the reach of Asociación de Pescadores Cabeza de Toro in regulating overfishing and harmful fishing practices. With the assistance of government sponsored courses in occupational and language skills, the hospitality industry can offer employment to fishermen, thus providing a revenue stream for fishermen without economic means who turn to harmful fishing practices. Additionally, these plans hinge upon the hospitality industry recognizing their dependence upon the coastal marine ecosystem to spur action - action that also comes in the form of preventing further destruction of mangrove sanctuaries, a restriction that may come either from the government or from within the hospitality or tourism industry. 


\section{Acknowledgements}

This research would not be possible without the mentorship of Jocelyn Widmer and the support of the Design Construction and Planning Department of the University of Florida. Furthermore, support provided by the Punta Cana Foundation and other local associations was crucial in data collection. Lastly the time and energy that was provided from the locals of Cabeza de Toro and fellow researchers renders this paper a true collaboration of individuals committed to conserving the coastal marine ecosystem and striving for mutually beneficial economic partnerships.

\section{References}

Avery, H. (2018). Blue finance: Why marine PPPs could be a win-win-win. Retrieved March 19, 2019, from https://www.euromoney.com/article/b18hg7vjwmy9hn/blue-finance-why-marine-pppscould-be-a-win-win-win

Brandt, M., Cooper, W., \& Polsenberg, J. (2003). Results of a coral reef survey of Punta Cana, Dominican Republic, with comparisons to past studies and other Caribbean reefs. The National Center for Caribbean Coral Reef Research. Rosenstiel School of Marine and Atmospheric Science, University of Miami, Florida

Burr, S. (2001). Status of the reef at Punta Cana, Dominican Republic: Preliminary survey and observations. Cornell University.

Steneck, R. S., Ph.D., \& Torres, R. E., Ph.D. (2015). El estado de los arrecifes de coral de la República Dominicana. Fundación PROPA-GAS. 